\title{
Commentary: Linking Movement Ecology with Wildlife Management and Conservation
}

\author{
Jennifer McGowan ${ }^{1 *}$ and Hugh P. Possingham ${ }^{1,2}$ \\ ${ }^{1}$ Centre for Biodiversity and Conservation Science, School of Biological Sciences, The University of Queensland, Brisbane, \\ QLD, Australia, ${ }^{2}$ Department of Life Sciences, Imperial College London, Silwood Park, UK
}

Keywords: animal movement, decision science, value of information, conservation planning, adaptive management

\section{A commentary on}

Linking Movement Ecology with Wildlife Management and Conservation

by Allen, A. M., and Singh, N. J. (2016). Front. Ecol. Evol. 3:155. doi: 10.3389/fevo.2015.00155

\section{OPEN ACCESS}

Edited by:

Danilo Russo,

Università degli Studi di Napoli

Federico II, Italy

Reviewed by:

Yossi Yovel,

Tel Aviv University, Israel

Francesco Ferretti,

University of Siena, Italy

*Correspondence:

Jennifer McGowan

j.mcgowan@uq.edu.au

Specialty section:

This article was submitted to

Conservation

a section of the journal

Frontiers in Ecology and Evolution

Received: 09 February 2016 Accepted: 14 March 2016

Published: 31 March 2016

Citation:

McGowan J and Possingham HP

(2016) Commentary: Linking

Movement Ecology with Wildlife

Management and Conservation.

Front. Ecol. Evol. 4:30

doi: 10.3389/fevo.2016.00030
Allen and Singh (2016) synthesize the ways movement ecology can inform wildlife management and conservation. The authors develop the "Movement Management Framework" - a stepwise decision tree for evaluating the types of data derived from animal movement studies and how that data can inform conservation decision-making. The authors provide a comprehensive review of the relevant literature but their decision-making framework ignores crucial aspects of modern decision science (Gregory et al., 2012). Here, we build on their framework by adapting it to better reflect current thinking around how movement information can be included in the decision-making process. Specifically, we highlight missing early steps in the planning stage related to prioritizing actions, questions to ask related to how movement data influences the selection of actions and other opportunities to refine plans through adaptive management.

First, we note that there is an important difference between the "broad goals" mentioned by Allen and Singh (2016) and "explicit quantitative objectives" (Tear et al., 2005). Without transforming broad goals into quantifiable objectives, decision makers run the risk of trying to solve an ill-defined problem, a common mistake of conservation prioritization (Game et al., 2013). For example, the goal of the author's Salmon case-study, whose populations are threatened by overfishing and hydro-electric dams, was "to reverse the decline of salmon stocks whilst maintaining activities like recreational and commercial fishing" (Allen and Singh, 2016). Quantifiable objectives that make this broad goal operational could be to: improve the passibility of rivers so that some average fraction, X\%, of a population enters upstream spawning habitat; or have a $90 \%$ chance of maintaining or increasing current catch per unit effort for commercial fishers. Setting quantifiable objectives so that actions can be prioritized and evaluated in space and time is the essential first step after broad goals have been defined. These objectives will then dictate the choice of actions and performance metrics used to evaluate if the actions have been successful (Figure 1).

Next, we emphasize that identifying and choosing actions should occur at the onset of the planning process, not the "Implementation stage" as the author's suggest. Implementing a conservation plan is largely a social and political process where communicating and engaging with a broad audience of managers, policy-makers, and stakeholders is key. Implementation often does not succeed or fail based on ecological factors, but because divergent values and perceptions were not adequately recognized or considered in the selection of actions during the planning stage (Biggs et al., 2011). 


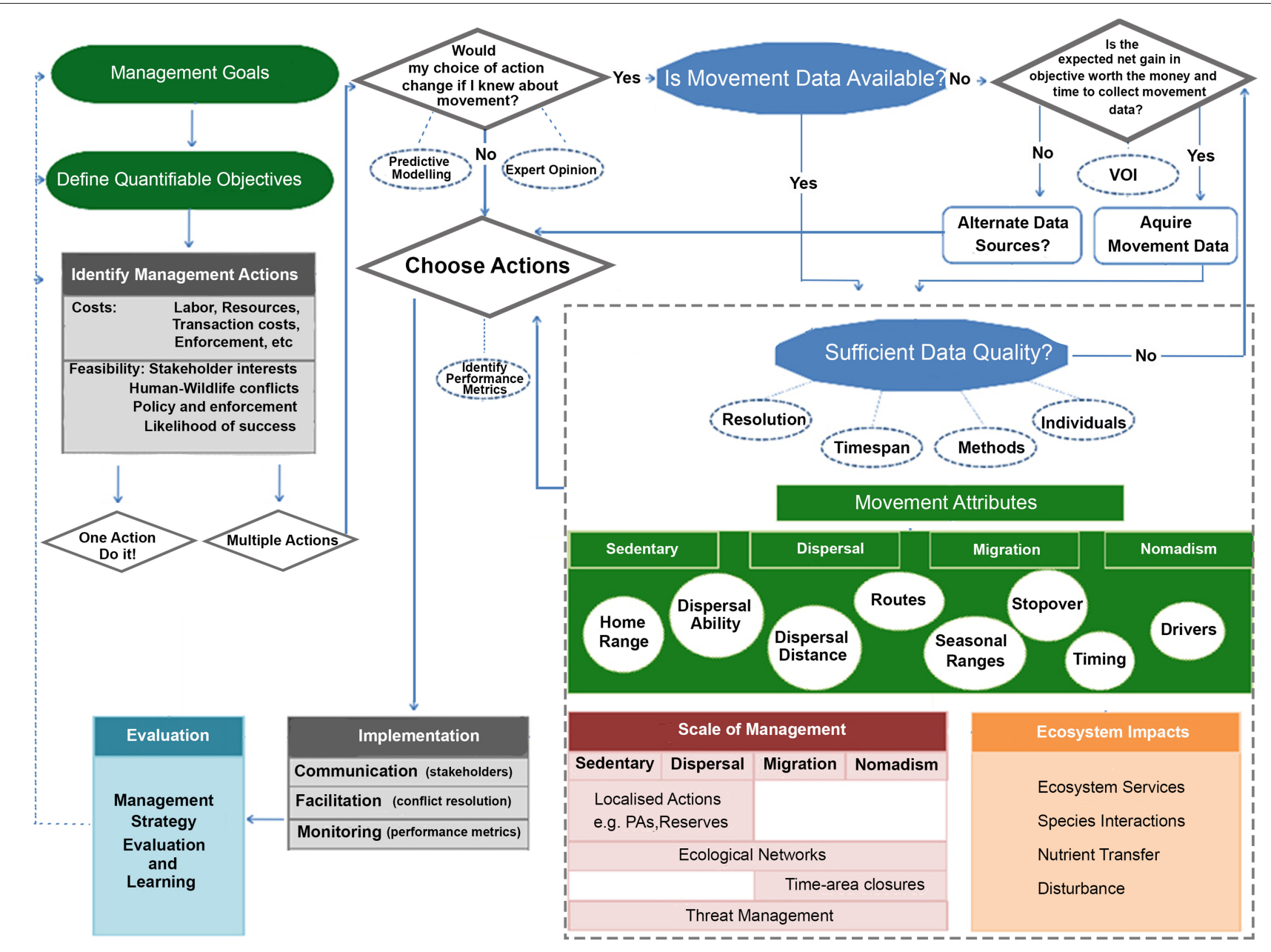

FIGURE 1 | The Movement Management framework, adapted from Allen and Singh (2016), provides a workflow for integrating movement ecology into conservation decision-making. Notable changes include steps to define quantifiable objectives, and identify and choose between management actions. Elements in and attached to diamonds are new additions to the workflow reflecting a focus of the value of information to inform decisions. Characteristics of movement data, such as quality, attributes, scale, and impacts aid the selection of actions in time and space.

Once we have a suite of quantifiable objectives we believe that managers and decision-makers need to list and screen possible actions. In some cases we may discover that only one action may be politically and economically feasible, in which case, managers may be better off just implementing it rather than waiting for more data to be collected. When multiple actions are possible, the author's are correct in stating the most costeffective action or set of actions delivering the greatest benefit, or a predetermined outcome, should be prioritized. For Atlantic Salmon populations, actions could be to strategically place fish ladders, alter water flow regimes, physically transport individuals, and reduce fishing effort. Prioritizing between these actions requires information on the costs, feasibility (economic, social, and technical; Figure 1) and the likelihood the action will achieve its objective (Carwardine et al., 2008). If we quantify these attributes up front we can often rule out certain actions.

Uncertainty is common in management decisions and the information derived from movement studies helps reduce uncertainty about both the system being managed, and the impact of the actions on the system (McDonald-Madden et al., 2010). However, acquiring new data is costly and time consuming. In the context of informing decisions, investing in more animal movement data should be carefully considered in terms of its ability to change or alter a management action and deliver a substantial expected benefit, not merely to refine parameters, build better models or better understand how animals move (Runge et al., 2011). Value of information analysis can assist with this conservation conundrum as it rigorously examines the trade-off between the costs and expected benefits (measured in terms of outcomes) of gathering new data (Maxwell et al., 2014; Canessa et al., 2015).

Our Figure 1 emphasizes that monitoring of performance metrics assists with evaluation, refining and learning during postimplementation stages. The author's suggest that evaluation may result in a redefinition of management goals in the long-term, but new information may also lead to iterative improvements in the near-term by refocusing objectives and/or defining new actions via adaptive management (Grantham et al., 2009). 
We hope this is a constructive addition to the framework offered by Allen and Singh (2016). They correctly place telemetry data into an adaptive management framework, a significant advance, but fail to prosecute the case for the value of movement information in terms of outcomes.

\section{AUTHOR CONTRIBUTIONS}

All authors contributed to the idea development, content, and writing of this submission.

\section{REFERENCES}

Allen, A. M., and Singh, N. (2016). Linking movement ecology with wildlife management and conservation. Front. Ecol. Evol. 3:155. doi: 10.3389/fevo.2015.00155

Biggs, D., Abel, N., Knight, A. T., Leitch, A., Langston, A., and Ban, N. C. (2011). The implementation crisis in conservation planning: could "mental models" help? Conserv. Lett. 4, 169-183. doi: 10.1111/j.1755-263X.2011.00170.x

Canessa, S., Guillera-Arroita, G., Lahoz-Monfort, J. J., Southwell, D. M., Armstrong, D. P., Chadès, I., et al. (2015). When do we need more data? A primer on calculating the value of information for applied ecologists. Methods Ecol. Evol. 6, 1219-1228. doi: 10.1111/2041-210X.12423

Carwardine, J., Wilson, K. A., Watts, M., Etter, A., Klein, C. J., and Possingham, H. P. (2008). Avoiding costly conservation mistakes: the importance of defining actions and costs in spatial priority setting. PLOS ONE 3:e2586. doi: 10.1371/journal.pone.0002586

Game, E. T., Kareiva, P., and Possingham, H. P. (2013). Six common mistakes in conservation priority setting. Conserv. Biol. 27, 480-485. doi: 10.1111/cobi. 12051

Grantham, H. S., Bode, M., McDonald-Madden, E., Game, E. T., Knight, A. T., and Possingham, H. P. (2009). Effective conservation planning requires learning and adaptation. Front. Ecol. Environ. 8, 431-437. doi: 10.1890/ 080151

Gregory, R., Failing, L., Harstone, M., Long, G., McDaniels, T., and Ohlson, D. (2012). Structured Decision Making: a Practical Guide to Environmental Management Choices. Oxford: John Wiley \& Sons.

\section{FUNDING}

JM supported by an ARC International Postgraduate Research Award. HPP supported by an ARC Laureate Fellowship.

\section{ACKNOWLEDGMENTS}

We thank all participants in the ARC Centre of Excellence workshop, "Connecting animal telemetry to conservation science" held in Feb 2015, for discussions and ideas that prompted this response.

Maxwell, S. L., Rhodes, J. R., Runge, M. C., Possingham, H. P., Ng, C. F., and McDonald-Madden, E. (2014). How much is new information worth? Evaluating the financial benefit of resolving management uncertainty. J. Appl. Ecol. 52, 12-20. doi: 10.1111/1365-2664.12373

McDonald-Madden, E., Probert, W. J. M., Hauser, C. E., Runge, M. C., Possingham, H. P., Jones, M. E., et al. (2010). Active adaptive conservation of threatened species in the face of uncertainty. Ecol. Appl. 20, 1476-1489. doi: 10.1890/090647.1

Runge, M. C., Converse, S. J., and Lyons, J. E. (2011). Which uncertainty? Using expert elicitation and expected value of information to design an adaptive program. Biol. Conserv. 144, 1214-1223. doi: 10.1016/j.biocon.2010.12.020

Tear, T. H., Kareiva, P., Angermeier, P. L., Comer, P., Czech, B., Kautz, R., et al. (2005). How much is enough? The recurrent problem of setting measurable objectives in conservation. Bioscience 55, 835-849. doi: 10.1641/0006-3568(2005)055[0835:HMIETR]2.0.CO;2

Conflict of Interest Statement: The authors declare that the research was conducted in the absence of any commercial or financial relationships that could be construed as a potential conflict of interest.

Copyright (C) 2016 McGowan and Possingham. This is an open-access article distributed under the terms of the Creative Commons Attribution License (CC BY). The use, distribution or reproduction in other forums is permitted, provided the original author(s) or licensor are credited and that the original publication in this journal is cited, in accordance with accepted academic practice. No use, distribution or reproduction is permitted which does not comply with these terms. 